\title{
PENERAPAN SISTEM TEKNOLOGI AUTOMATISASI GUNA MENUNJANG PROSES COAL SUPPLY CHAIN DI ROM STOCKPILE PT. ADARO INDONESIA
}

\author{
Rahman Arif \\ Coal Mining and ROM Management Section, \\ Coal Production and Product Assembly Department, \\ Mining Division, PT. Adaro Indonesia
}

\begin{abstract}
ABSTRAK
ROM Stockpile merupakan fasilitas yang sangat penting pada rantai pasok batubara PT. Adaro Indonesia karena merupakan gudang yang setiap aktivitas didalamnya harus dipastikan berjalan dengan excellent. Terdapat 11 ROM Stockpile di seluruh wilayah operasional PT. Adaro Indonesia yang perlu di kontrol dan di manage agar tidak menimbulkan efek pada proses selanjutnya. Adapun kesalahan proses selanjutnya yang dimaksud seperti kesalahan kualitas batubara yang diangkut ke tongkang akibat miss informasi dan laporan volume stock ROM yang keliru. Untuk mengatasi hal ini PT. Adaro Indonesia menerapkan system automatisasi dan teknologi pada ROM stockpile nya agar mencegah error pada proses selanjunya tersebut. Adapun upaya system yang di terapkan adalah pemasangan RFID dan perangkatnya pada in-out ROM, serta pengambilan data stock ROM harian dengan menggunakan fotogrametri (drone) untuk meningkatkan accuracy pelaporan stock ROM sebagai acuan perencanaan hauling hariannya. Dengan penerepan sistem-sistem yang dijelaskan diatas, hasil aktualnya sesuai dengan yang diharapkan yakni membuat kesalahan pada proses selanjutnya akibat operasional ROM frekuensinya menjadi menurun dan aktivitas di ROM berjalan semakin efektif dan efisien.
\end{abstract}

Kata kunci: ROM Stockpile, Accuracy, RFID, Fotogrametri

\begin{abstract}
ROM Stockpile is a very important facility in the coal supply chain of PT. Adaro Indonesia because it is a warehouse that every activity in it must be ensured to run excellently. There are 11 ROM Stockpiles in all operational areas of PT. Adaro Indonesia that needs to be controlled and managed so as not to have an effect on the next process. The subsequent process errors are referred to as coal quality errors transported to the barge due to miss information and incorrect ROM stock volume reports. To overcome this, PT. Adaro Indonesia applies an automation system and technology to its stockpile ROM to prevent errors in the next process. The system effort applied is the installation of RFID and its devices in in-out ROM, as well as daily stock ROM data collection using photogrammetry (drones) to improve reporting accuracy of ROM stock as a reference for daily hauling planning. With the foregoing of the systems described above, the actual results are as expected, which is to make mistakes in the next process due to the operational frequency of the ROM being decreased and the activities in the ROM running more effectively and efficiently.
\end{abstract}

Keywords: ROM Stockpile, Accuracy, RFID, Photogrammetry 


\section{A. PENDAHULUAN}

\section{A.1. Latar Belakang}

Berkibar di bawah naungan kelompok perusahaan PT Adaro Energy Tbk,dan merupakan perusahaan tambang batubara single site terbesar di Indonesia. Pada tahun 2018, PT Adaro Indonesia memproduksi 52 juta ton batubara berkualitas tinggi yang rendah sulphur, NOx, dan debu atau dikenal sebagai Envirocoal. Terdapat 4 jenis product batubara yang ditawarkan yaitu E5000, E4900, E4700, dan WB.

Proses operasional penambangan batubara di PT Adaro Indonesia mengelola 3 pit, yaitu Tutupan, Paringin, dan Wara. Tiap pit memiliki lapisan batubara (seam) dengan quality yang bervariasi. Seam tersebut akan diklasifikasikan menjadi raw material berdasarkan kalorinya kemudian Raw material ini diangkut dan disimpan didalam ROM (Run of Mine) yang jumlahnya sebanyak 11 ROM dimana masing-masing ROM memiliki karakteristik yang berbeda-beda.

Raw material ini kemudian dicampur dan diangkut untuk menjadi produk, proses pencampuran dan pengangkutan raw material dari ROM ke port dilakukan dengan menggunakan unit trailler double vessel dengan jarak tempuh terjauh $87 \mathrm{KM}$. Kemudian akan dilakukan proses dumping raw material ke crusher sesuai dengan product yang diinginkan sebelum akhirnya dilakukan proses shipping.

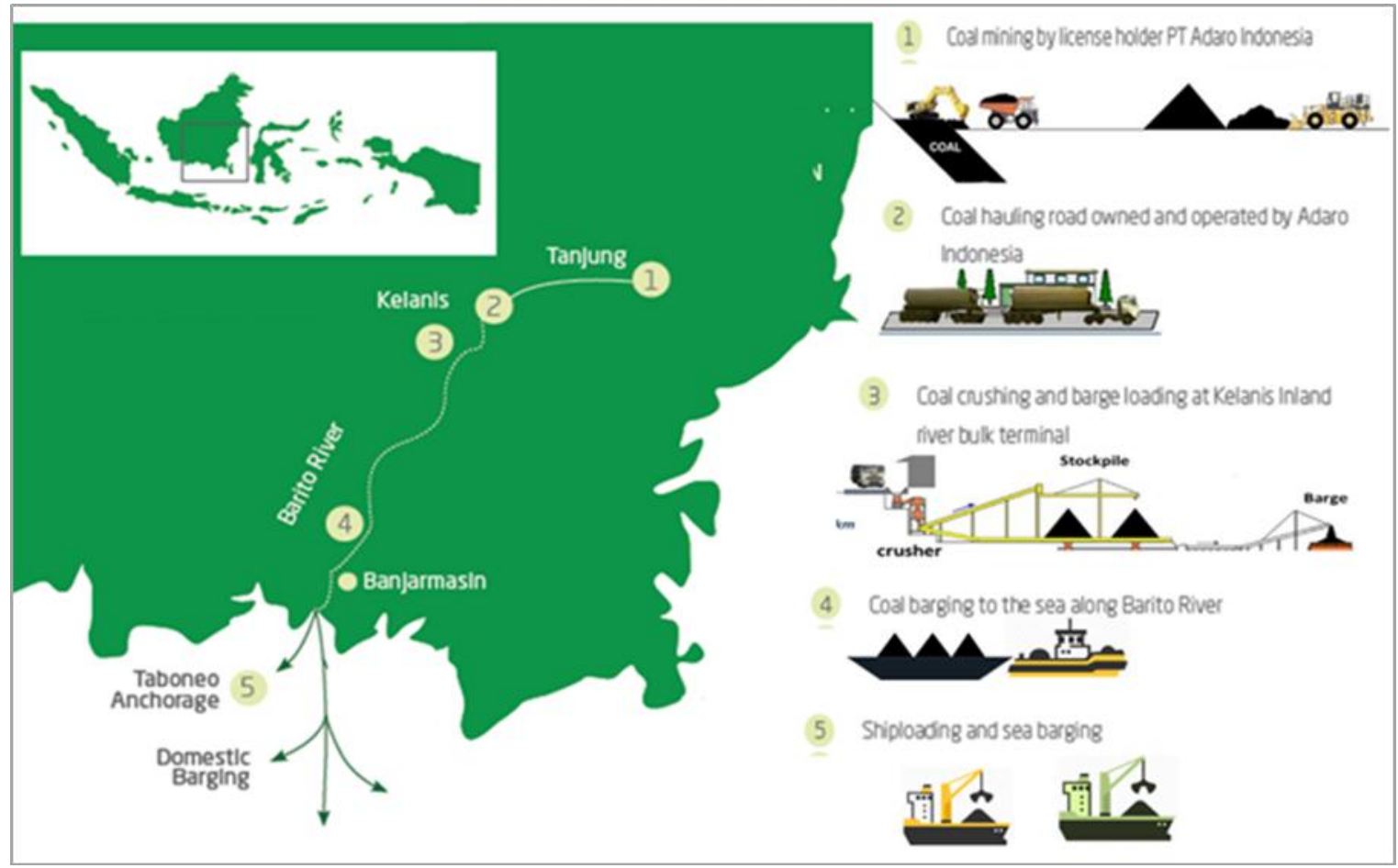

Gambar 1. Business Process PT. Adaro Indonesia.

Dalam bisnis proses PT Adaro Indonesia, departemen Coal Production \& Product Assembly menjalankan fungsi proses sebagai berikut :

Coal Getting

: proses penggalian batubara yang sudah dikupas batuan penutupnya, pengangkutan batubara ke ROM dan dumping batubara di ROM 
Loading Coal at ROM : proses pemuatan batubara dari tempat penyimpanan sementara ROM (Run of Mine) ke trailer.

Coal Hauling : proses pengangkutan batubara dari ROM menuju pelabuhan Kelanis. Dumping Coal at Hopper \& KROM adalah proses penuangan batubara di mulut Hopper Crusher di pelabuhan Kelanis.

Di bawah departemen Coal Production \& Product Assembly terdapat 3 section yang Memiliki tugas dan peran yang sama pentingnya yakni Coal Mining \& ROM Management Section, Coal Hauling Section dan Coal Assembly Section. Coal Mining \& ROM Management Section berfungsi menjalankan proses Coal Getting sampai dengan Loading Coal at ROM. CMR Section selaku penanggungjawab pengelolaan batubara dari pit menuju ROM berkomitmen untuk meniadakan defect baik secara kualitas maupun kuantitas terhadapa product batubara yang akan dikirim pada proses selanjutnya.

\section{A.2. Tujuan}

Penerapan sistem ini sesuai dengan misi utama yakni memuaskan kebutuhan pelanggan dan nilai Excellence serta melaksanakan PDCA secara konsisten dan memberikan upaya terbaik untuk mencapai keseimbangan optimal antara kualitas dan efisiensi.

Tabel 1. Visi, Misi dan Nilai PT Adaro Indonesia.

\begin{tabular}{|c|c|c|c|}
\hline VISI & MISI & & NILAI \\
\hline $\begin{array}{l}\text { Menjadi grup } \\
\text { perusahaan } \\
\text { tambang dan } \\
\text { energi Indonesia } \\
\text { yang terkemuka }\end{array}$ & $\begin{array}{l}\text { - Memuaskan } \\
\text { kebutuhan pelanggan } \\
\text { - Mengembangkan } \\
\text { karyawan } \\
\text { - Menjalin kemitraan } \\
\text { dengan pemasok } \\
\text { - Mendukung } \\
\text { pembangunan } \\
\text { masyarakat dan } \\
\text { Negara } \\
\text { - Mengutamakan } \\
\text { keselamatan dan } \\
\text { kelestarian lingkungan } \\
\text { - Memaksimalkan nilai } \\
\text { bagi bagi pemegang } \\
\text { saham }\end{array}$ & $\begin{array}{c}\text { Meritocracy } \\
\text { Openness } \\
\text { Respect } \\
\mathbf{R} \\
\text { Excellence }\end{array}$ & $\begin{array}{l}\text { - Hanya memberikan data dan } \\
\text { informasi berdasarkan fakta } \\
\text { - Mendukung pengembangan } \\
\text { bawahan dengan memberikan } \\
\text { peluang yang sama } \\
\text { - Berani menyampaikan pendapat } \\
\text { yang berbeda demi kepentingan } \\
\text { perusahaan } \\
\text { - Memperlakukan semua orang } \\
\text { dengan rasa hormat dengan } \\
\text { menghargai perbedaan yang ada } \\
\text { - Melaksanakan PDCA secara } \\
\text { konsisten demi mencapai tujuan } \\
\text { perusahaan } \\
\text { - Memberikan upaya yang terbaik } \\
\text { untuk mencapai keseimbangan yang } \\
\text { optimal antara kualitas dan efisiensi } \\
\text { - Berusaha semaksimal mungkin } \\
\text { untuk melampaui harapan pelanggan }\end{array}$ \\
\hline
\end{tabular}

\section{A.3. Pendekatan Pemecahan Masalah}

Proses pencampuran dan pengangkutan batubara PT. AI dilakukan disepanjang $87 \mathrm{KM}$ jalur hauling oleh dua mitra kerja PT PAMA dan PT SIS. Proses ini meliputi proses pengangkutan raw material dari ROM, mobilisasi raw material, dan proses dumping. 


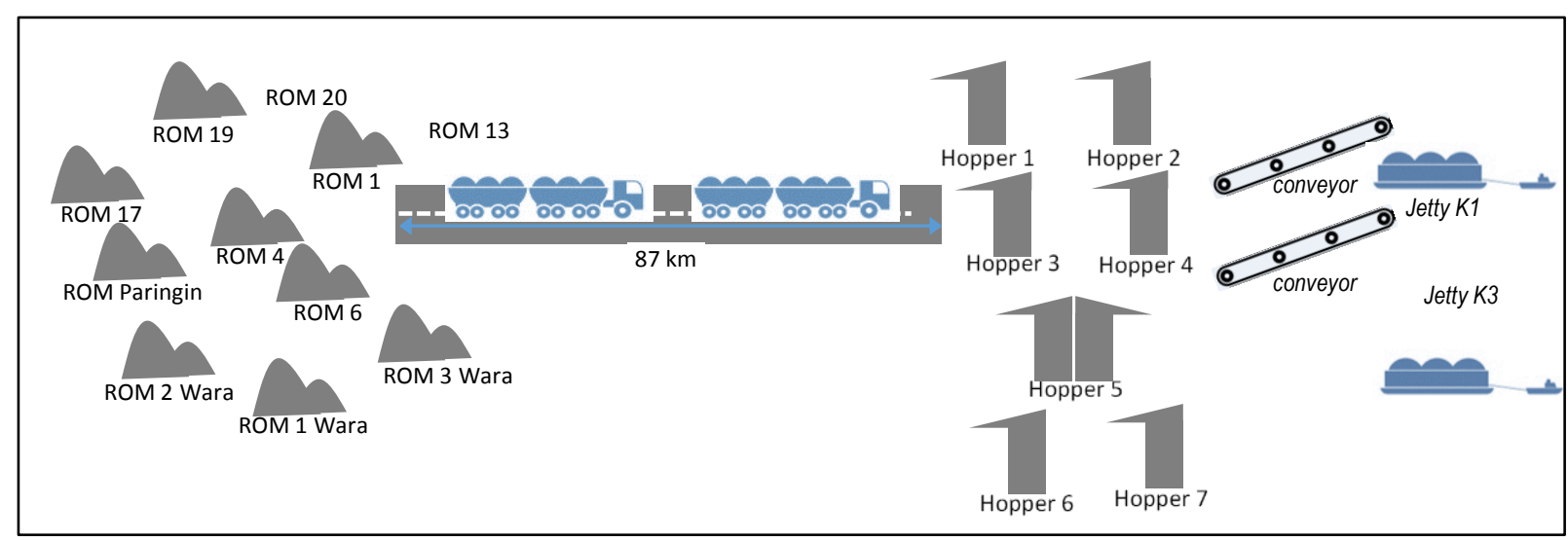

Gambar 2. Ilustrasi Proses Hauling.

Terdapat total 35 raw material yang tersimpan di 11 ROM yang berbeda. Dimana masing-masing raw material memiliki karakteristik berdasarkan kandungan kalorinya.

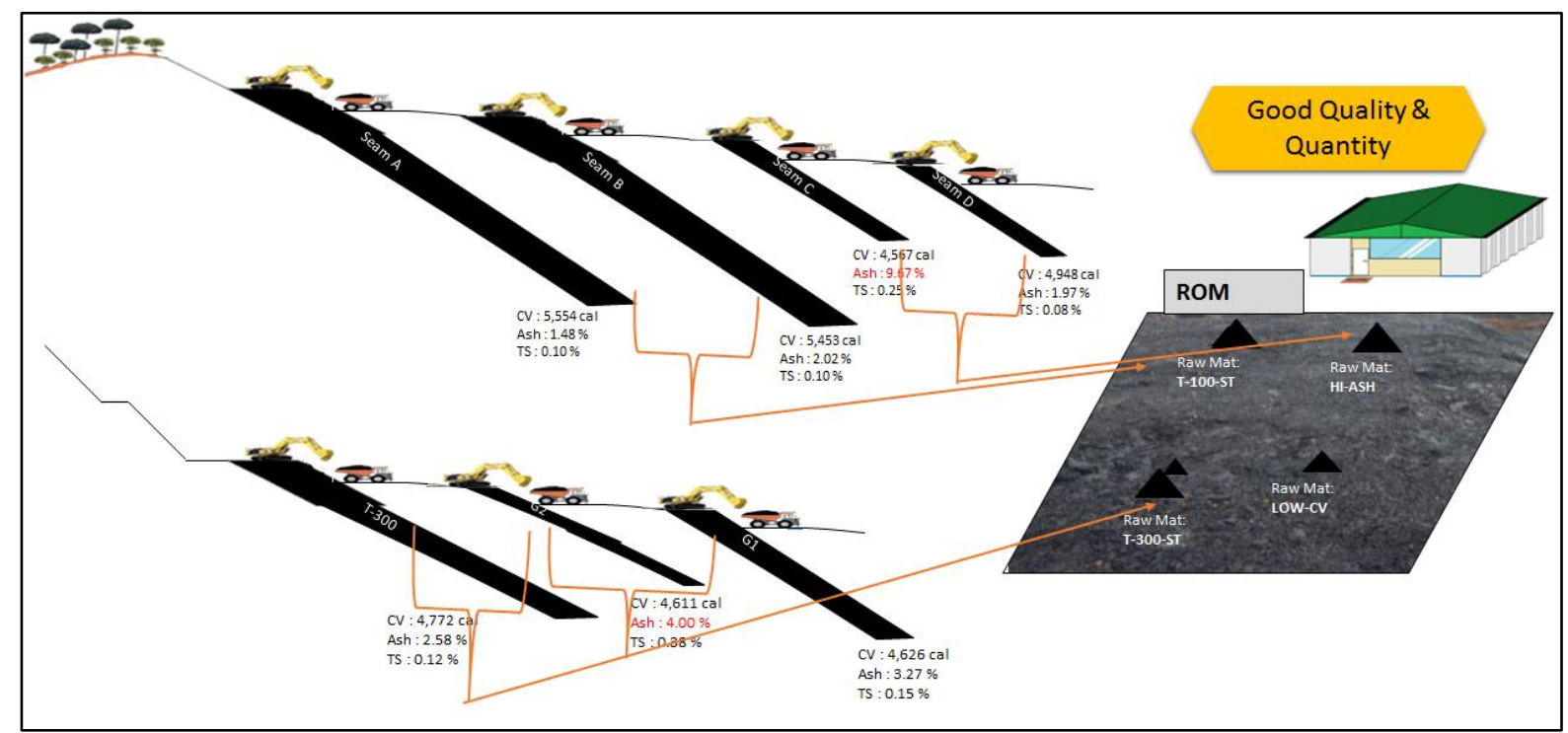

Gambar.3 Skenario Klasifikasi Raw Material.

Raw material ini kemudian dilakukan proses blending untuk menghasilkan 3 product akhir dimana masing-masing product akhir memiliki spesifikasi kalori yang berbeda. Sepanjang proses coal supply ini sangat memungkinkan sekali terjadinya miss informasi yang akan berdampak kepada mis quality terhadap product yang akan kita pasarkan, ketika terjadi ketidaksesuaian supply passing unit maka akan mengakibatkan Out of Specification (OOS) pada product akhir. Menurut ECA Academy, OOS adalah suatu hasil dari suatu proses dimana hasil tersebut jatuh diluar rentang kriteria yang disepakati oleh perusahaan. Disamping itu juga pelaporan stock ROM yang akurat memiliki peranan yang tidak kalah penting karena merupakan salah satu acuan yang akan dijadikan dasar oleh tim Coal Assembly dalam membuat perencanaan hauling tiap jam-nya yang diterjemahkan oleh tim CMR kedalam bentuk yang namanya Q-Pass atau rekomendasi raw material.. 


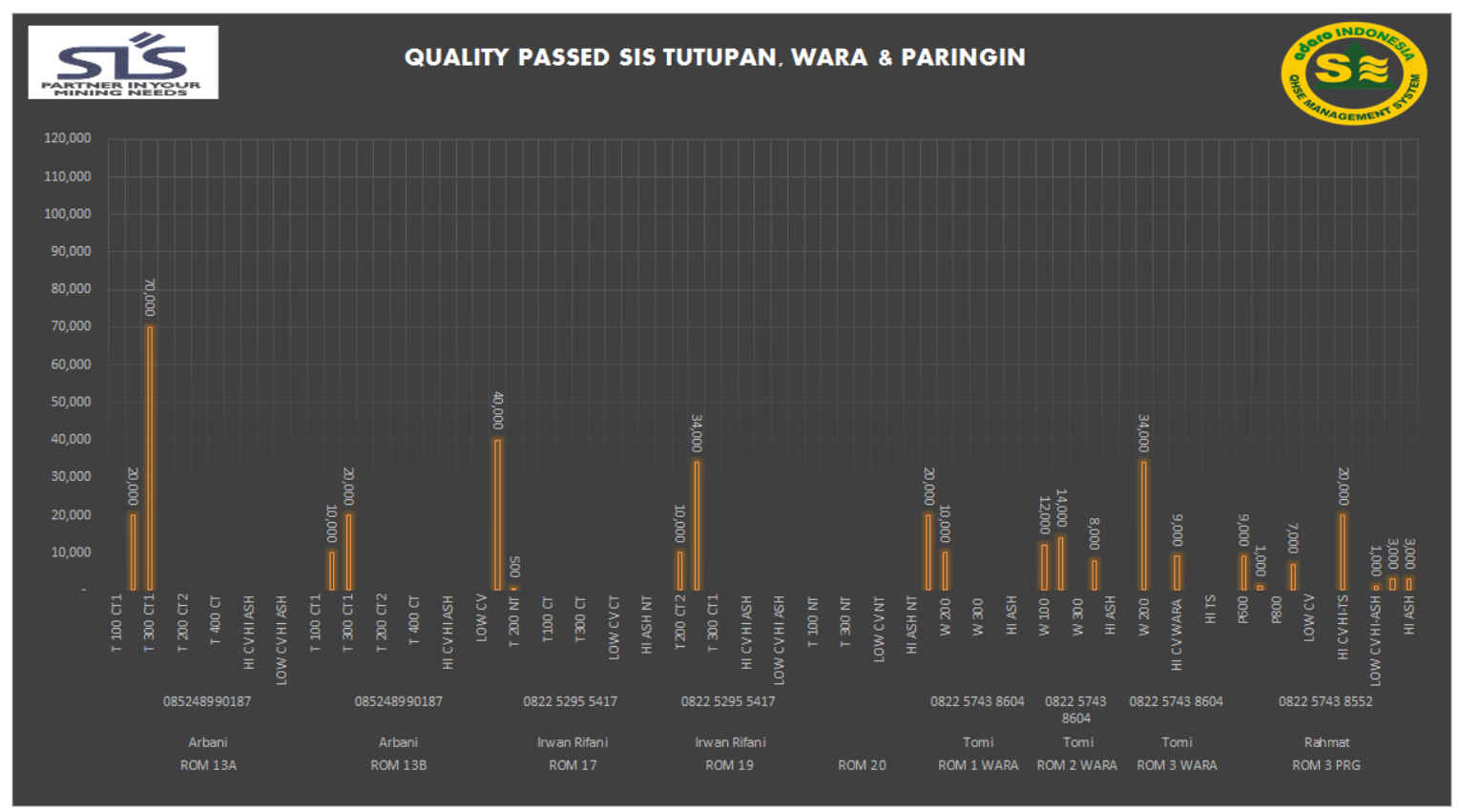

Gambar 4. Contoh Quality Passed Stock ROM.

\section{B. METODOLOGI}

Terkait metodologi yang digunakan dalam proses penerapan teknologi ini yakni menganut sistem metodologi PDCA atau yang sering dikenal dengan Kaizen yang tujuannya untuk mencapai continuous improvement yang di implemetasikan di ruang lingkup Coal Production dan Product Assembly Department dengan penyajian data secara kuantitatif. Konsep PDCA meski cukup sederhana, namun masih menjadi alternative pertama dalam pengelolaan bisnis proses. Perubahan, perbaikan dan pengembangan proses-proses akan sering terjadi menggunakan pola ini dengan konsep mencari akar masalah yang sederhana.

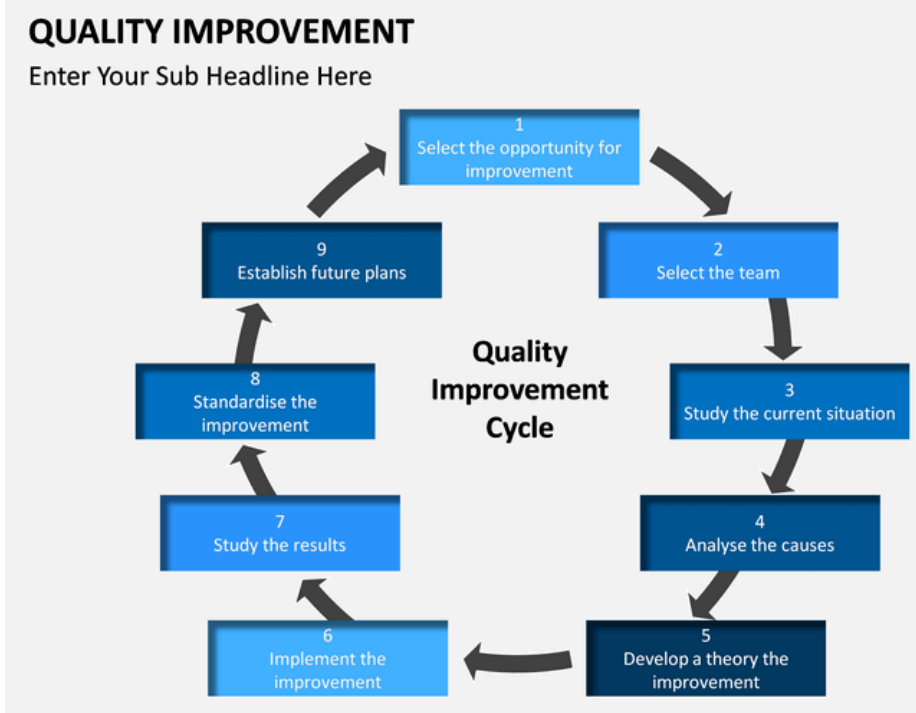

Gambar 5. Siklus Metodologi PDCA. 
Di samping Metode PDCA dalam proses perencanaan pengangkutan kita juga menggunakan pendekatan Bill Of Material yang dapat kita defenisikan produk akhir yang terdiri dari daftar item, bahan, atau material yang dibutuhkan untuk merakit, mencampur atau memproduksi produk akhir.

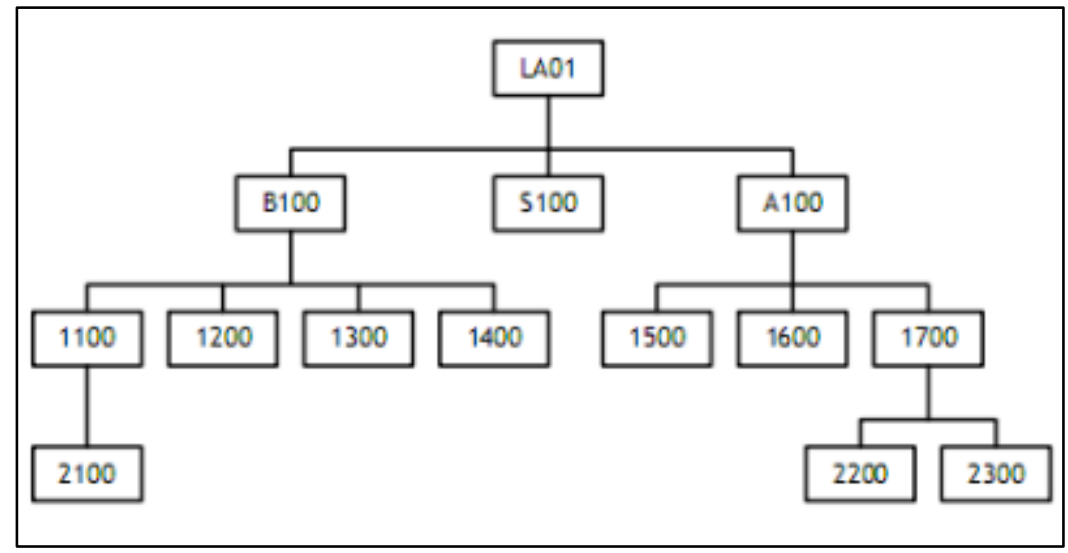

Gambar 6. Struktur Multilevel Bill Of Material

\section{HASIL DAN PEMBAHASAN}

Berdasarkan hasil pengamatan kinerja proses sebelum dilakukannya perbaikan, maka diperlukan sistem automatisasi yang dapat mendeteksi dan menyimpan data baik secara kualitas dan kuantitas yang disajikan secara online agar dapat dimonitoring bersama dengan data-data penunjang lainnya sehingga operasional ROM dan coal supply secara umum dapat berjalan efektif dan efisien dengan menghilangkan human error akibat proses kerja yang manual.

Kompleksitas operasional mulai dari jumlah trailer, raw material dan ROM serta panjangnya proses pengangkutan batubara ke pelabuhan menjadi alasan bahwa dibutuhkannya suatu sistem manajemen fleet untuk membantu kegiatan operasional di proses coal supply PT. Adaro Indonesia.

\section{C.1. RFID(Radio Frequency Identification)}

RFID adalah proses identifikasi suatu objek dengan menggunakan frekuensi transmisi radio. RFID menggunakan frekuensi radio untuk membaca informasi dari sebuah device kecil yang disebut tag atau transponder (Transmitter + Responder). Tag RFID akan mengenali diri sendiri ketika mendeteksi sinyal dari device yang kompatibel, yaitu Reader. RFID adalah teknologi identifikasi yang fleksibel, mudah digunakan, dan sangat cocok untuk operasi otomatis. RFID mengkombinasikan keunggulan yang tidak tersedia pada teknologi identifikasi yang lain. RFID dapat disediakan dalam device yang hanya dapat dibaca saja (Read Only) atau dapat dibaca dan ditulis (Read/Write), tidak memerlukan kontak langsung maupun jalur cahaya untuk dapat beroperasi, dapat berfungsi pada berbagai variasi kondisi lingkungan, dan menyediakan tingkat integritas data yang tinggi. Sebagai tambahan, karena teknologi ini sulit untuk dipalsukan, maka RFID dapat menyediakan tingkat keamanan yang tinggi. Pada sistem RFID umumnya, tag atau transponder ditempelkan pada suatu objek. Setiap tag membawa dapat membawa informasi yang unik, di antaranya: serial number, model, warna, tempat perakitan, dan data lain yang dibutuhkan dari objek tersebut. Ketika tag ini melalui medan yang dihasilkan oleh pembaca RFID yang kompatibel, tag akan mentransmisikan informasi yang ada pada tag kepada pembaca RFID, sehingga proses identifikasi objek dapat dilakukan. Sistem RFID terdiri dari empat komponen, di antaranya seperti dapat dilihat pada gambar berikut : 


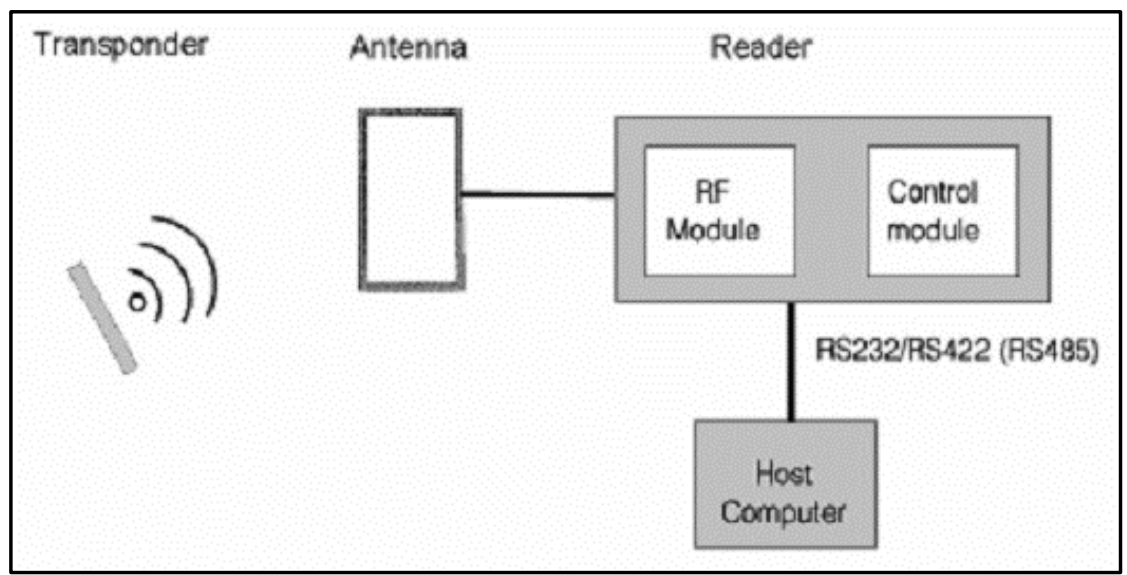

Gambar 7. Sistem RFID.

Tag ini adalah device yang menyimpan informasi untuk identifikasi objek. Tag RFID sering juga disebut sebagai transponder. Antena berfungsi untuk mentransmisikan sinyal frekuensi radio antara pembaca RFID dengan tag RFID. Pembaca RFID adalah device yang kompatibel dengan tag RFID yang akan berkomunikasi secara wireless dengan tag. Software Aplikasi adalah aplikasi pada sebuah workstation atau PC yang dapat membaca data dari tag melalui pembaca RFID. Baik tag dan pembaca RFID(reader) dilengkapi dengan antena sehingga dapat menerima dan memancarkan gelombang elektromagnetik. Sebuah pembaca RFID harus menyelesaikan dua buah tugas, yaitu: Menerima perintah dari software aplikasi berkomunikasi dengan tag RFID Pembaca RFID adalah merupakan penghubung antara software aplikasi dengan antena yang akan meradiasikan gelombang radio ke tag RFID. Gelombang radio yang diemisikan oleh antena berpropagasi pada ruangan di sekitarnya. Akibatnya data dapat berpindah secara wireless ke tag RFID yang berada berdekatan dengan antena.

Berdasarkan catu daya tag, tag RFID dapat digolongkan menjadi:

- Tag Aktif: yaitu tag yang catu dayanya diperoleh dari batere, sehingga akan mengurangi daya yang diperlukan oleh pembaca RFID dan tag dapat mengirimkan informasi dalam jarak yang lebih jauh. Kelemahan dari tipe tag ini adalah harganya yang mahal dan ukurannya yang lebih besar karena lebih komplek. Semakin banyak fungsi yang dapat dilakukan oleh tag RFID maka rangkaiannya akan semakin komplek dan ukurannya akan semakin besar.

- Tag Pasif: yaitu tag yang catu dayanya diperoleh dari medan yang dihasilkan oleh pembaca RFID. Rangkaiannya lebih sederhana, harganya jauh lebih murah, ukurannya kecil, dan lebih ringan. Kelemahannya adalah tag hanya dapat mengirimkan informasi dalam jarak yang dekat dan pembaca RFID harus menyediakan daya tambahan untuk tag RFID.

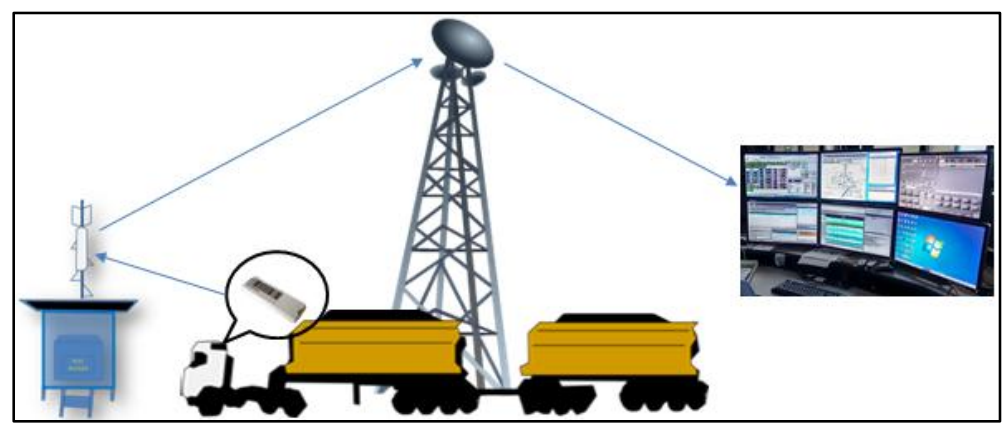

Gambar 8. Instalasi RFID di PT. Adaro Indonesia. 
Di PT. Adaro Indonesia Instalasi unit RFID dilakukan pada inlet dan outlet ROM, halte, Hopper dan sepanjang jalur hauling untuk mendeteksi unit yang masuk dan keluar secara otomatis dengan memanfaatkan jaringan internal Adaro yang sudah tersedia disepanjang jalur hauling dengan kualitas yang baik. Adapun tag yang dipakai yaitu tag pasif dengan pertimbangan cost yang lebih efisien dan penggunaannya yang lebih praktis. Selain itu perawatan RFID dilakukan oleh internal dan tidak memerlukan biaya bulanan serta hardware dikerjakan oleh PA Project dan aplikasi dikerjakan oleh IT adaro serta vendor sehingga evaluasi performansinya dapat dilakukan setiap saat. Aplikasi RFID dikembangkan secara internal dan dapat dimodifikasi menyesuaikan kebutuhan user. Dalam melakukan pemilihan komponen, kami menggunakan Decision Analysis Work Sheet (DAW) yang meliputi parameter sebagai berikut:

Tabel 2. Decision Analysis Worksheet Pemilihan Reader

\begin{tabular}{cll}
\hline & & Alternative Pemilihan Reader \\
\hline No & \multicolumn{1}{c}{ Objective } & \multicolumn{1}{c}{ Pertimbangan } \\
\hline 1 & Kehandalan alat & Radius pembacaan objek yang bergerak \\
2 & Fleksibilitas & Compatible dengan sistem yang sudah ada \\
3 & Kemudahan instalasi & Pengalaman yang sudah pernah dilakukan oleh tim \\
4 & Regulasi & Bekerja pada frekuensi radio bebas, tidak memerlukan izin \\
\hline
\end{tabular}

Tabel 3. Decision Analysis Worksheet Pemilihan Antenna

\begin{tabular}{cll}
\hline & & \multicolumn{1}{c}{ Alternative Pemilihan Reader } \\
\hline No & \multicolumn{1}{c}{ Objective } & \multicolumn{1}{c}{ Pertimbangan } \\
\hline 1 & Kesesuaian fungsi & $\begin{array}{l}\text { Memiliki sudur pancaran 45-180 derajat, } \\
\text { sesuai dengan instalasi RFID yang diletakkan di sisi in-out ROM }\end{array}$ \\
2 & Kehandalan alat & Memiliki penguatan sinyal tinggi 20dB \\
3 & Kemudahan instalasi & Dimensinya sehingga jumlah orang yang menginstalasi dapat di minimalisir \\
4 & Biaya instalasi & Mencari yang lebih efisien \\
\hline
\end{tabular}

Tabel 4. Decision Analysis Worksheet Pemilihan Sumber Listrik

\begin{tabular}{cll}
\hline \multicolumn{2}{c}{ Alternative Pemilihan Sumber Listrik } \\
\hline No & \multicolumn{1}{c}{ Objective } & \multicolumn{1}{c}{ Pertimbangan } \\
\hline 1 & Kemudahan instalasi & Dapat dikerjakan internal departemen saja \\
2 & Kehandalan alat & Tidak tergantung sumber listrik manapun \\
3 & Kecepatan instalasi & Tidak memakan waktu lama \\
4 & Biaya instalasi & Mencari yang lebih efisien \\
\hline
\end{tabular}

Setelah proses pemilihan alat, desain dan pengujian jaringan serta pembcaan data RFID kemudian diIntegrasikan ke aplikasi HTS (Hauling Tracking System) merupakan aplikasi internal PT. Adaro indonesia yang digunakan sebagai pusat data operasional produksi hauling. Aplikasi ini dapat diakses oleh semua karyawan PT. AI yang bekerja di Coal Production dan Product Assembly Department. 


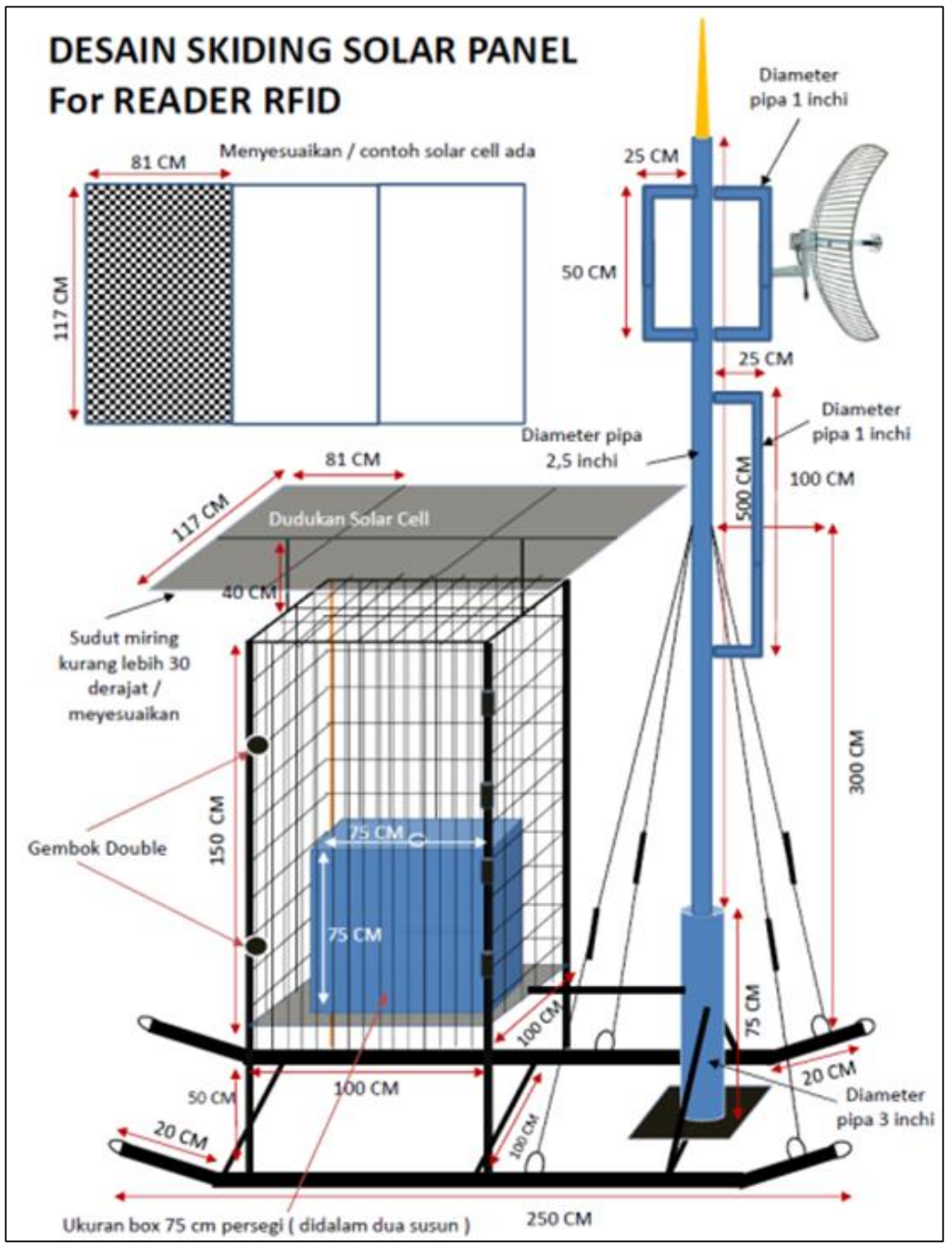

Gambar 9. Desain Box.

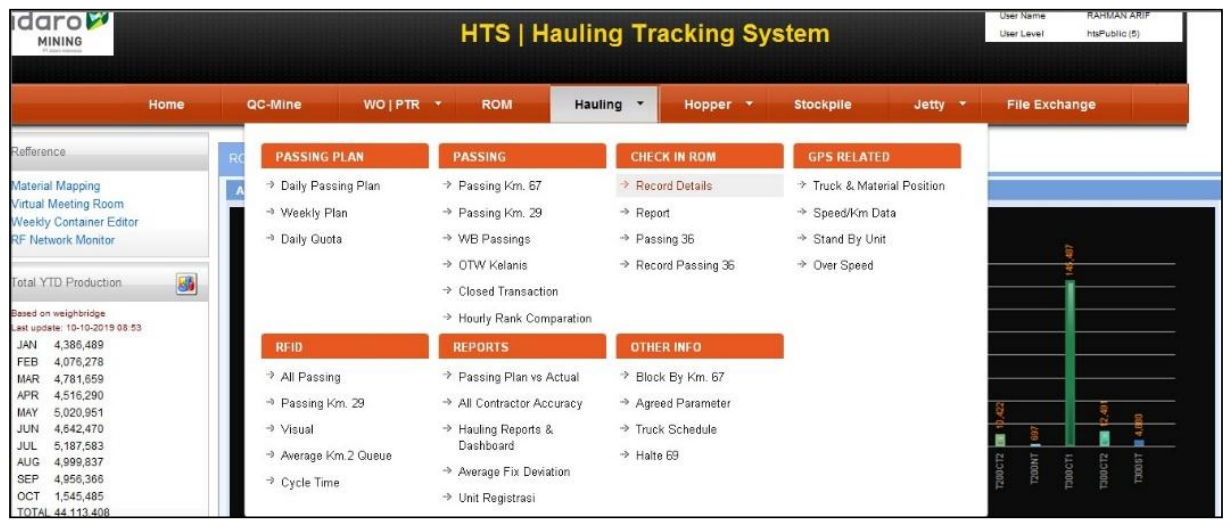

Gambar 10. Penambahan pada fitur HTS.

\section{C.2. Fotogrametri Pengukuran Stock ROM}

Metode pemetaan dengan system fotogrametri digital dan LIDAR (Light detection and ranging) menggunakan pesawat udara tanpa awak ini merupakan suatu seni, ilmu dan teknologi untuk 
mendapatkan objek dan informasi diatas permukaan bumi secara fisik. Dengan melalui proses data akuisisi, pengukuran, pengolahan dan interpretasi citra foto yang direkam melalui sensor digital atau laser yang terpasang pada pesawat udara tanpa awak(UAV) dapat menghasilkan gambaran permukaan bumi dalam format digital yang disajikan berupa orthopoto (Peta foto tegak 2 dimensi, Digital Surface Model (DSM), Digital Terrain Model (DTM) yang kemudian diolah menjadi model 3 dimensi, peta garis dan kontur yang nantinya akan diolah lebih lanjut untuk analisis spesifik sesuai dengan kebutuhan pengguna. Tantangan yang dihadapi dalam bisnis proses tambang selama ini adalah menyeimbangkan antara biaya operasi dengan resiko pekerjaan yang cukup tinggi. Pemetaan area, ataupun stockpile analysis yang dilakukan meliputi keterlibatan tenaga manusia didalamnya, dan karena area yang dipetakan sering kali tidak selalu human-friendly. Maka resiko yang tinggi juga seringkali harus dihadapi oleh para pekerja tambang. Oleh karena itu fungsi drone disini hadir untuk memberikan impact agar operasional dapat efektif dan efisien. Pada bisnis proses Coal Mining dan ROM Management fotogrametri drone dibutuhkan untuk mendapatkan data stock ROM harian yang mendekati akurasi laser/survey sehingga menghilangkan adjustment visual (manual adjustment) dalam penentuan volume stock ROM. Kemudian hasil ini akan di share ke rekan dispatch coal assembly agar dijadikan sebagai acuan rekomendasi material dalam pembuatan perencanaan pengangkutan tiap jamnya. Dengan adanya teknologi ini harapannya material yang direncanakan tiap jam-nya diangkut dapat sesuai dengan apa yang diharapkan sehingga tidak ada lagi pengalihan material ataupun waiting cargo dikarenakan kesalahan dalam informasi jumlah tonase stock harian sehingga operasional secara kualitas dan kuantitas dapat berjalan lancar. Adapun yang dilakukan oleh tim CMR dalam hal ini untuk penerapan ini adalah:

1. Trial akurasi drone vs laser di ROM

2. Training kepada crew CMR terkait manual penggunaan dan pengolahan data pada aplikasi

3. Pembuatan checklist $\mathrm{P} 2 \mathrm{H}$ drone sebelum terbang

- Contoh Trial Pengukuran Fotogrametri ROM 1 Wara

Berikut disampaikan proses dan hasil pengukuran fotogrametri vs laser di ROM 1 Pit Wara:

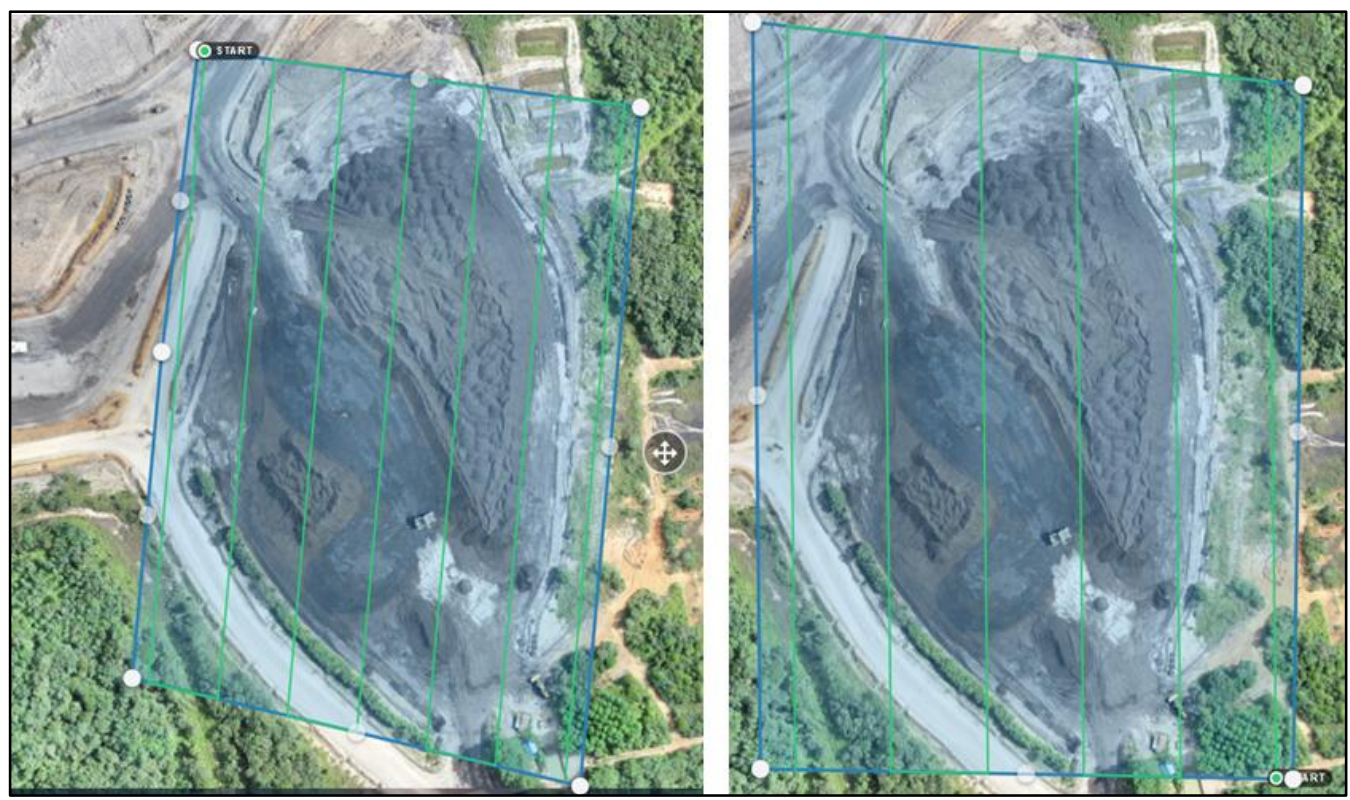

Gambar 11. Flight Plan ketinggian 75 dan 100 meter 


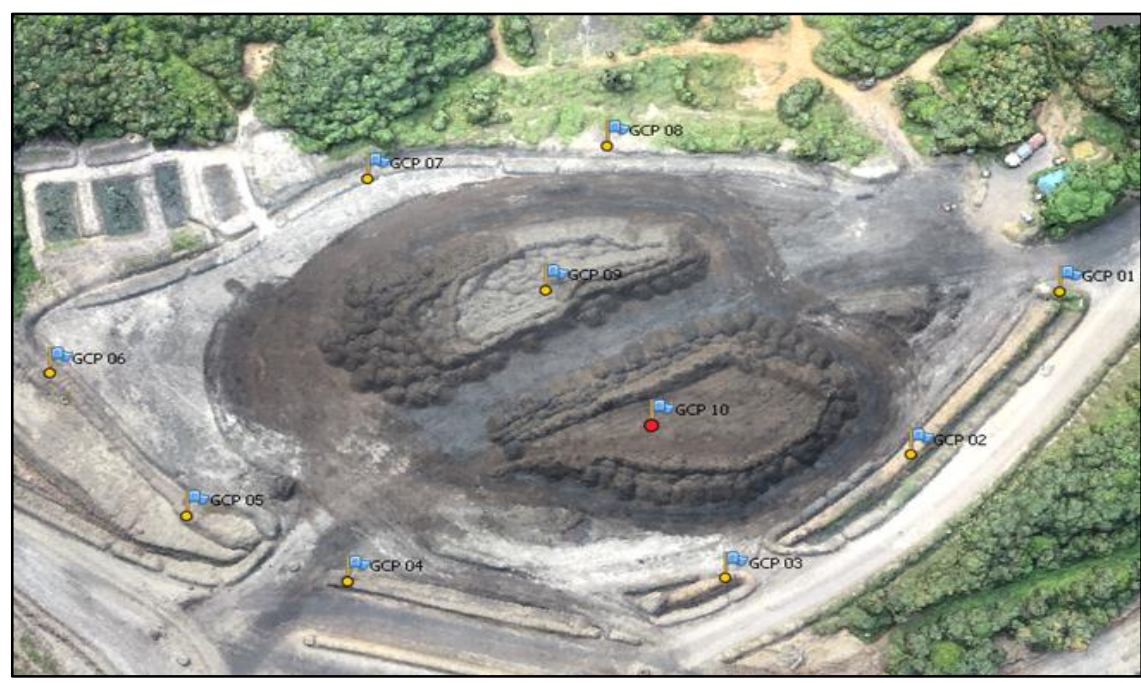

Gambar 12. Posisi Ground Control Point.

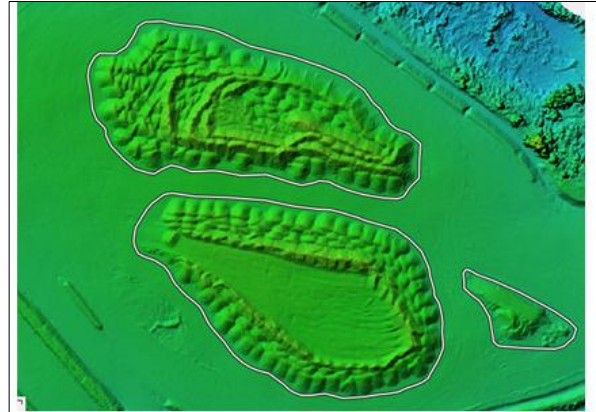

Resolution: Point density:
$3.99 \mathrm{~cm} / \mathrm{pix}$ 627 points $/ \mathrm{m}^{2}$

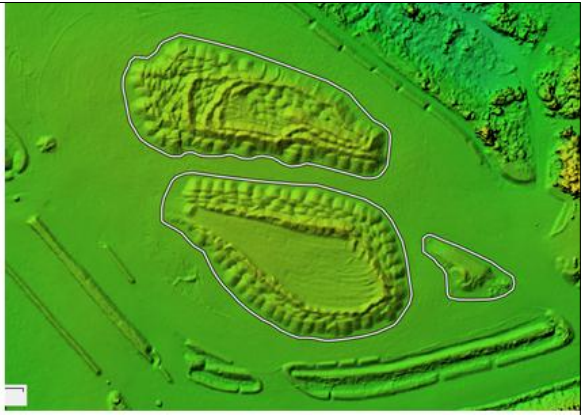

$5.32 \mathrm{~cm} / \mathrm{pix}$

353 points $/ \mathrm{m}^{2}$

Gambar 13. DEM Quality 75 dan 100 Meter.

Tabel 5. Volume Comparison Flight 75M.

\begin{tabular}{ccccc}
\hline \multicolumn{5}{c}{ High Quality Dense Cloud ALT 75M } \\
\hline BDY & TLS & UAV & DEVIASI & \% \\
P1 & 20269.36 & 19847.36 & 421.99 & 2.1 \\
P2 & 18351.39 & 17616.75 & 734.64 & 4 \\
P3 & 864.18 & 840.36 & 23.82 & 2.8 \\
Total & 39484.93 & 38304.47 & 1180.46 & 3 \\
\hline \multicolumn{5}{c}{ Tabel 6. Volume Comparison Flight $100 \mathrm{M}$} \\
\hline \multicolumn{5}{c}{ High Quality Dense Cloud ALT 100M } \\
\hline BDY & TLS & UAV & DEVIASI & \% \\
P1 & 20269.36 & 19858 & 411.35 & 2 \\
P2 & 18351.39 & 17626.39 & 725.01 & 4 \\
P3 & 864.18 & 842.51 & 21.66 & 2.5 \\
Total & 39484.93 & 38326.91 & 1158.02 & 2.9 \\
\hline
\end{tabular}




\section{KESIMPULAN}

Penerapan dan implementasi teknologi automasi yang dilakukan pada proses coal supply di PT. Adaro Indonesia ini memberikan impact positif bagi proses operasional, antara lain:

- RFID yang dikombinasikan dengan aplikasi penunjang sebagai tool monitoring fleet hauling yang terintegrasi memberikan kemudahan kepada seluruh stakeholder di sepanjang jalur pada rantai proses pengangkutan batubara untuk mengakses dan memonitor supply trailer dari ROM to Port secara online

- Dengan adanya RFID meningkatkan accuracy baik secara quality maupun quantity karena sudah mengeliminir proses pencatatan secara manual

- RFID dan Aplikasi penunjangnya dapat menjadi bahan evaluasi terhadap kinerja pada proses pengangkutan di PT. Adaro Indonesia seperti analisa cycle time dan produktivitas trailer sehingga dapat meningkatkan juga optimasi supply trailer ke hopper/crusher

- Fotogrametri drone sangat membantu sekali dalam masalah pelaporan volume stock ROM secara harian untuk acuan tim dispatch dalam perencanaan pengangkutan karena prosesnya yang cukup efektif dan efisien dan accuracy yang masih dalam range toleransi jika kita bandungkan dengan visual adjustment

\section{DAFTAR PUSTAKA}

Kaur, M., Manjeet, S., Neeraj, M., Parvinder, S., (2011). RFID Technology Principles, Advantages, Limitation and Its Applications, International Journal of Computer and Electrical Engineering, Vol.3, No.1, February, 2011, 151-153

Pengertian dan Komponen RFID, data diperoleh melalui situs internet:

http://elektronika-dasar.web.id/pengertian-dan-komponen-radio-frequency-identification-rfid/

PT. Adaro Indonesia.(2017). Manual BarscalesRF V.2.0, Tanjung Tabalong

Widihatmoko, Deny (2017): Technical Standar Adaro Indonesia PAH-04-001. PT. Adaro Indonesia. Tanjung Tabalong

Widihatmoko, Deny (2017): Technical Standar Adaro Indonesia PAH-02-001. PT. Adaro Indonesia. Tanjung Tabalong 